Article

\title{
Characteristics of Deformation and Damping of Cement Treated and Expanded Polystyrene Mixed Lightweight Subgrade Fill under Cyclic Load
}

\author{
Weihua Lu ${ }^{1}{ }^{1}$, Linchang Miao ${ }^{2}$, Junhui Zhang ${ }^{3, *}$, Yongxing Zhang ${ }^{1}$ and Jing $\mathrm{Li}^{2}$ \\ 1 School of Civil Engineering, Nanjing Forestry University, Nanjing 210037, China; \\ whlnjfu@njfu.edu.cn (W.L.); zhanguongxing81@aliyun.com (Y.Z.) \\ 2 Institute of Geotechnical Engineering, Southeast University, Nanjing 210096, China; \\ lc.miao@seu.edu.cn (L.M.); whl361@163.com (J.L.) \\ 3 National Engineering Laboratory of Highway Maintenance Technology, \\ Changsha University of Science \& Technology, Changsha 410114, China \\ * Correspondence: zjhseu@csust.edu.cn; Tel.: +86-137-8716-2685
}

Received: 8 December 2018; Accepted: 27 December 2018; Published: 4 January 2019

\begin{abstract}
To investigate the deformation and damping characteristics of cement treated and expanded polystyrene (EPS) beads mixed lightweight soils, this study conducted a series of triaxial shear tests cyclic loading for different confining pressures, cement contents, and soil categories. Through repeated loading and unloading cycles, axial accumulative strain, resilient modulus, and damping ratio versus axial total strain were analyzed and the mechanical behavior was revealed and interpreted. Results show that the resilient modulus increases with increasing confining pressure and cement content. A decreasing power function can be used to fit the relationship between the resilient modulus and the axial total strain. Although sandy lightweight specimens usually own higher resilient modulus than silty clay lightweight specimens do, the opposite was also found when the axial total strain is larger than $8 \%$ with $50 \mathrm{kPa}$ confining pressure and $14 \%$ cement content. For damping ratio the EPS beads mixed lightweight soil yields a weak growth trend with increasing axial total strain and a small reduction with higher confining pressure and cement content. For more cementations, the damping ratio of the sandy lightweight soil is always smaller than the silty clay lightweight soil. Nonetheless, the differences of damping ratios that were obtained under all of the test conditions are not significant.
\end{abstract}

Keywords: EPS lightweight soil; cyclic load; axial accumulative strain; resilient modulus; damping ratio

\section{Introduction}

With the rapid development of transportation in China, highways or high-speed railways would inevitably encounter the situation of soft soil foundations. How to deal with unacceptable settlements of embankments on these foundations has become one of the most challenging tasks for engineers [1,2]. Traditionally, the composite foundation and plastic drainage are always utilized to reinforce the soft soil foundation to diminish the potential settlement $[3,4]$. However, use of embankments with lightweight backfill material, such as expanded polystyrene (EPS) blocks (also called EPS geo-foam) or EPS beads mixed with soil and binder [5,6], can also reach this goal. Obviously, the latter is much more time saving, cost-effective, and even environmentally friendly.

Since Frydenlund [7] firstly reported that the EPS geo-foam was used as an embankment fill in Norway, more and more studies about this artificial material have been conducted and its good performances have been confirmed. For example, replacing the typical embankment fill material in highways [5], diminishing the maximum lateral earth pressure of a reinforced soil platform [8], 
and reducing the swelling pressure by expansion of soil behind the retaining wall [9], etc. At the same time, a lightweight fill consisting of dredged soil and air foam and cement (i.e., EPS beads) was adopted to reduce the embankment self-weight on soft foundations in Japan [10]. Miki [11] pointed out that the EPS beads could even reduce the weight of the fill to a great extent, even to be $50 \%$, which is of great beneficial for the post-construction settlement control. Liu et al. [12] pointed out that the unconfined compressive strength of the lightweight fill, as well as the shear strength and stiffness, increases considerably if the cement-soil ratio of $10 \%$ to $15 \%$ is used. Moreover, Miao et al. [13] inspected the mechanical properties of the lightweight fill through a series of road performance tests, verifying that embankments with the lightweight backfill obtain an obviously smaller settlement over embankments with the conventional lime-stabilized fill.

As a subgrade filling replacement material, the lightweight soil should have good bearing capacity and deformation properties under static loading, but it also needs good mechanical performance under repeated traffic loading. As early as 2002, Minegishi et al. [14] has pointed out that the mechanical behaviors of lightweight soil under static and dynamic loads would be quite different from the natural soils. At present, the research on the dynamic characteristics of lightweight soils mainly focuses on the acquisition of basic dynamic characteristics parameters and the effects of various influencing factors. For example, Gao et al. [15] analyzed the characteristics of skeleton curve, dynamic shear modulus, and damping ratio of EPS composite soils based on nineteen combined axial-torsional tests on hollow cylinder specimens. Through resonant column and cyclic triaxial tests on sand-EPS bead mixtures, El-Sherbiny et al. [16] discovered that the material damping is relatively unaffected at small shear strains but it increases at larger strains, and the decrease in shear stiffness with increasing bead content occurs at all strain levels. Moreover, Alaie et al. [17] carried out a series of laboratory tests to evaluate the monotonic, cyclic, and post-cyclic behavior of the contact interface between lightweight soil and reinforced geogrid. Nonetheless, the road performance of the lightweight fill, especially the mechanical behavior under complex loading conditions as well as the difference with different natural soils is still not clear.

In this study, a series of triaxial shear tests, under repeated loading-unloading conditions, were conducted to investigate the characteristics of deformation and damping of EPS beads-mixed lightweight soils. The axial accumulative strain, the resilient modulus and the damping ratio versus the axial total strain under different confining pressures, cement contents, and soil categories were systematically analyzed. Subsequently, a further understanding of the mechanical properties of the EPS mixed lightweight soil under cyclic loading was obtained.

\section{Materials and Methods}

\subsection{Materials}

The silty clay and sand (as shown in Figure 1) that were adopted in this study were taken from the Beigu lake of Zhenjiang City, which belongs to the Yangtze River basin in the eastern China. Large particles that were more than $2 \mathrm{~mm}$ were removed from the material by a sieve. According to the Unified Soil Classification System (ASTM D2487-11) [18], the sand belongs to the poorly graded fine sand (SP). Its coefficient of uniformity $(\mathrm{Cu})$ and coefficient of gradation $(\mathrm{Cc})$ are 1.41 and 0.69 , respectively. The grain size distributions of these two soils are illustrated in Figure 2. The main physical property indices of the silty clay are summarized in Table 1. 


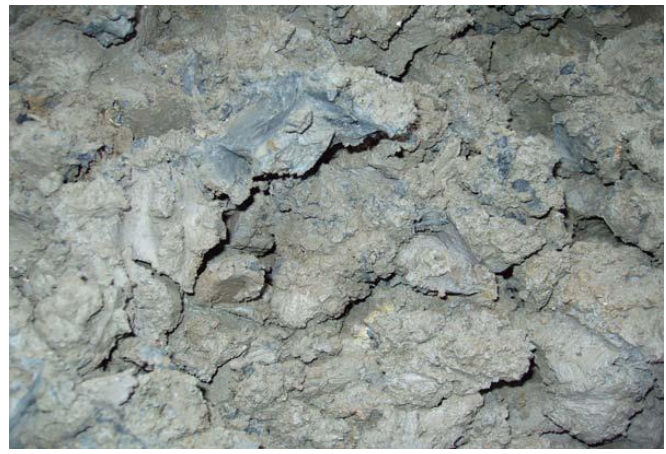

(a)

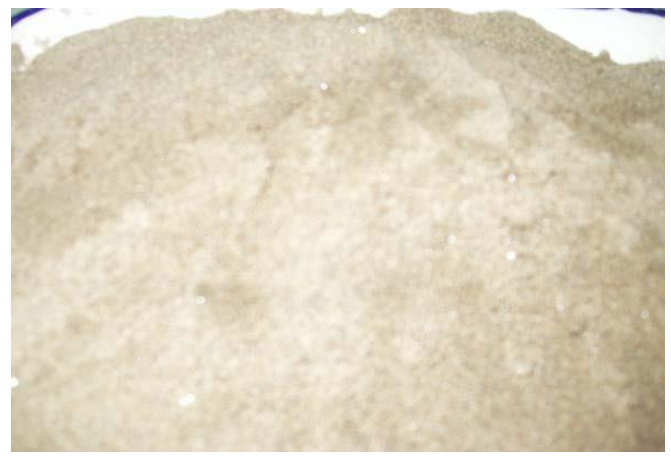

(b)

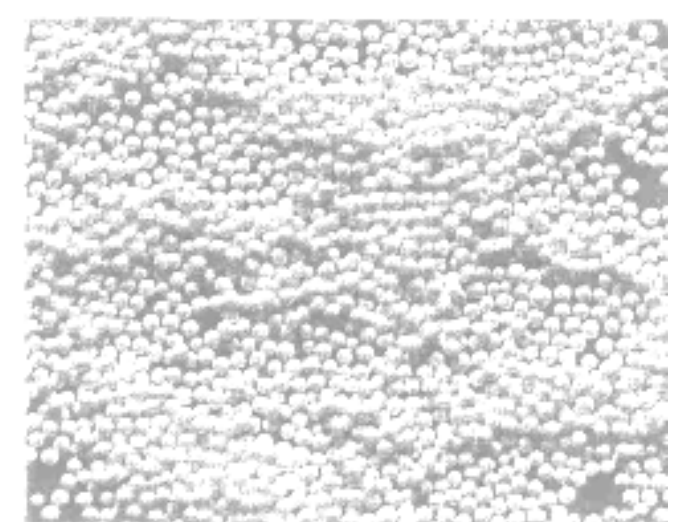

(c)

Figure 1. Test materials used in the tests: (a) Silty clay; (b) Sand; and, (c) expanded polystyrene (EPS) beads.

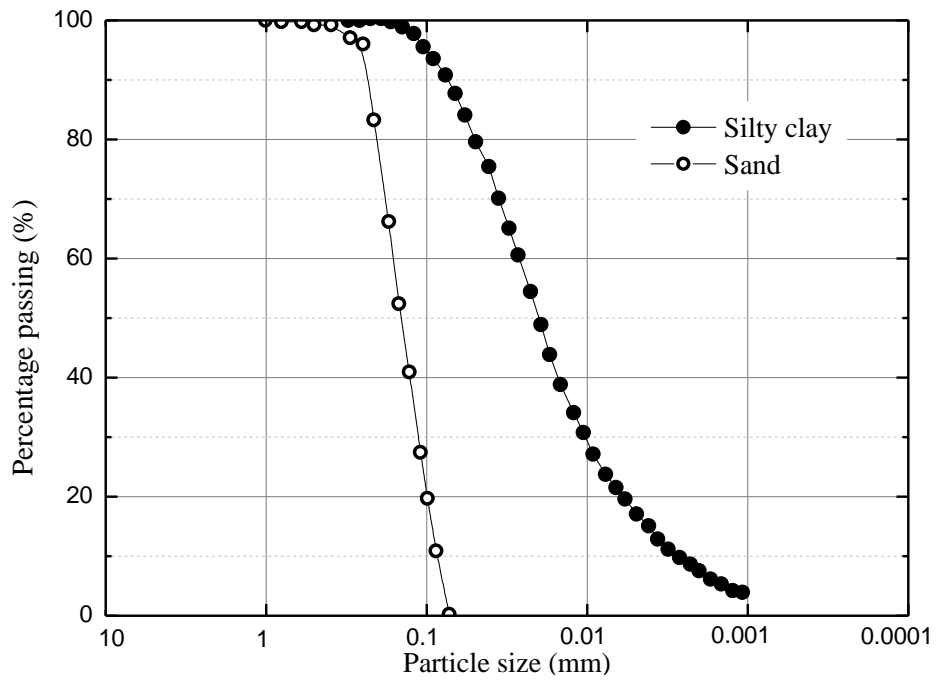

Figure 2. Particle size distribution of soils used in the tests.

Table 1. Properties of the test silty clay.

\begin{tabular}{cccccc}
\hline $\begin{array}{c}\text { Water Content } \\
(\mathbf{\%})\end{array}$ & $\begin{array}{c}\text { Natural Density } \\
\left(\mathbf{g} / \mathbf{c m}^{\mathbf{3}}\right)\end{array}$ & $\begin{array}{c}\text { Liquid Limit } \\
(\mathbf{\%})\end{array}$ & $\begin{array}{c}\text { Plastic Limit } \\
(\mathbf{\%})\end{array}$ & Liquidity Index & Plasticity Index \\
\hline 52.6 & 1.75 & 44.2 & 23.0 & 1.4 & 21.2 \\
\hline
\end{tabular}


The EPS beads (as shown in Figure 1c) that were used in this study are manufactured by expandable polystyrene resin (from Suzhou Yizhan Purification Technology Co., Ltd. in China, 2017), containing microscopic cells that are foamed with pentanes or butanes. When the beads are formed after the blowing agent expands, volume of individual resin beads would increase by up to 40 to 50 times. The particle size of the round EPS beads ranges from 3 to $5 \mathrm{~mm}$, with the bulk unit weight of $0.013 \mathrm{~g} / \mathrm{cm}^{3}$.

The Portland cement (P. O. 32.5) (Nanjing Pukou Youwei Cement Products Factory Co., Ltd. in China, 2018) was used as a binding material to bind the EPS beads with sand or silty clay, and water was used to carry out the hydration reaction and facilitate the mixing process. Subsequently, the lightweight mixture can be easier to be compacted to carry the required load after an appropriate curing time.

\subsection{Specimen Preparation}

To make standard triaxial specimens, the silty clay and sand were used as the raw material soil, and then cement and water were added by mass percent while the EPS beads were added by volume ratios. The cement content $a_{w}$ (or cement weight) was designed to be $14,16,18$, and $20 \%$, relative to the weight of silty clay or sand. The volume ratios of the sand/silty clay together with cement to the EPS beads were determined at 1:1. A machine mixer (Wuxi Chiba Mixing Equipment Co., Ltd. in China, 2014) was utilized to mix the mixture thoroughly, with the capacity bucket rotating at certain speeds of $102 / 204 / 388 \mathrm{r} / \mathrm{min}$. The untreated soil was weighed to get the mass and firstly placed into the mixer, then the cement and the EPS beads were uniformly added into the soil and forcibly stirred for $5 \mathrm{~min}$. At last, water was poured into the mixing bucket and stirred more than 5 min until the components were evenly distributed.

Once the lightweight soil was mixed thoroughly and stirred evenly, the weighed mixtures were put into a triple-piece mold and then compacted for 25 times in five layers, using a mini compaction hammer with a $295.8 \mathrm{~g}$ weight and a $12 \mathrm{~cm}$ drop distance. The size of the triple-piece mold was $3.91 \mathrm{~cm}$ in diameter and $8.0 \mathrm{~cm}$ in height. After compaction, the specimens were cured in a standard box with the temperature of $20{ }^{\circ} \mathrm{C}$ and the humidity of $100 \%$ for $24 \mathrm{~h}$. Afterwards, the specimens were taken out and immediately put in plastic bags for a curing time of 14 days.

\subsection{Test Procedure}

To investigate the physical and mechanical properties of EPS composite soil, conventional testing methods, such as the unconfined compression test, the uniaxial compression test, the direct shear test, and the triaxial compression test, are always adopted. The current researches paid many attentions to interpret the mechanical behavior and its influence on strength, deformation, and failure modes under static loading [19-21]. However, as embankment fill subgrades, the EPS composite soil is likely to undertake cyclic loadings, such as the traffic loading or the seismic loading. Therefore, the dynamic properties of the EPS mixed lightweight fill are a concern for engineering [14]. In general, the conventional dynamic characteristic study on EPS composite soil is focused on the dynamic stress-state relationship, dynamic modulus and strength, damping ratio, and so on [15].

Although the conventional resonance column test and dynamic triaxial test would be the most commonly used methods to conduct the above research activities, the modification or new use of conventional test instruments can also fulfill some research tasks. Therefore, a conventional strain-controlled triaxial apparatus (Nanjing Soil Instrument Factory Co., Ltd. (type-ASPTTS) in China, 2012) was adopted to carry out the consolidated undrained (CU) test under confining pressures of 50,100, and $150 \mathrm{kPa}$ [22]. The CU test procedures in ASTM D4767-11 [23] were followed in the laboratory. In the traditional dynamic cyclic loading test, a cyclically changing direction dynamic load is applied to the specimen. However, the cyclic loading in this study is defined as a different repeated loading process. For example, under a confining pressure of $50 \mathrm{kPa}$, the specimen was firstly loaded by lifting the triaxial chamber with a rate of axial strain to a predetermined total strain value, 
and then the acted load was gradually removed by declining the chamber. Subsequently, the reloading and reunloading action would be developed repeatedly. In the scheme of this experimental study (see Figure 3), each specimen underwent nine repeated actions and the corresponding unloading strains were $2 \%, 3 \%, 4 \%, 6 \%, 8 \%, 10 \%, 12 \%, 14 \%$, and $16 \%$, respectively.

To reveal the dynamic properties of the EPS composite soil under repeated loading conditions, several affecting factors, such as the stress state, soil type, and cement content should be evaluated, as well as the effect variation on mechanical characteristics. The stress state and loading-unloading times were also checked for accessing the dynamic response of the lightweight material. Several mechanical indexes were evaluated, such as the axial cumulative strain, the resilient modulus, and the damping ratio.

\begin{tabular}{l|}
\hline Prepare the specimen \\
\hline Install the specimen in the triaxial test chamber \\
\hline Check all parts of the instrument \\
\hline Bring the axial load piston into contact the specimen \\
\hline Saturate the specimen by the back pressure method (in steps) \\
\hline Apply the desired confining pressure \\
\hline Let the specimen consolidation \\
\hline Apply axial load to the specimen using a rate of axial strain of the chamber \\
\hline Stop at first strain of $2 \%$ or others and then unloading the previous applied load \\
\hline Reloading the specimen to the next desired strain of $3 \%$ or others \\
\hline Repeat the above cyclic loading until the axial total strain arrives at $16 \%$ \\
\hline Record load and pore pressure of each step \\
\hline When shear is completed, remove the specimen and check relevant parameters \\
\hline
\end{tabular}

Figure 3. Test procedure for the consolidated undrained (CU) test in the laboratory under cyclic loading.

\section{Results and Discussion}

\subsection{Axial Cumulative Strain}

The axial cumulative strain is one of the important indexes to characterize the deformation ability of the lightweight soil. In this study, the axial cumulative strain is defined as the residual strain when the overlying load is removed. As shown in Figure 4 for sandy lightweight soil, the axial cumulative strain increases with the increasing cyclic loading times, as well as the axial total strain of the specimen. There exists a good linear relationship between the axial cumulative strain and the axial total strain (see Figure 5), and the ratio of axial cumulative strain to axial total strain remains constant. The same also applies to the tested silty clay lightweight soil specimens. However, the influence of confining pressure, cement content, and soil type on the ratio is very small through inspecting all of the tested specimens in this study (not shown here). 


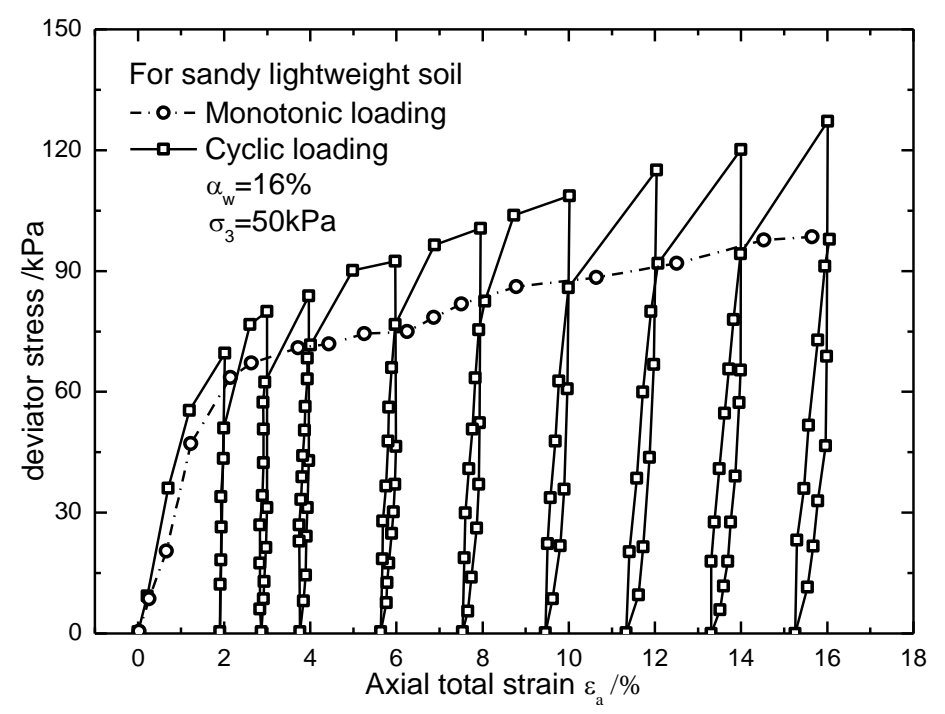

Figure 4. Typical stress-strain curve under monotonic loading and cyclic loading.

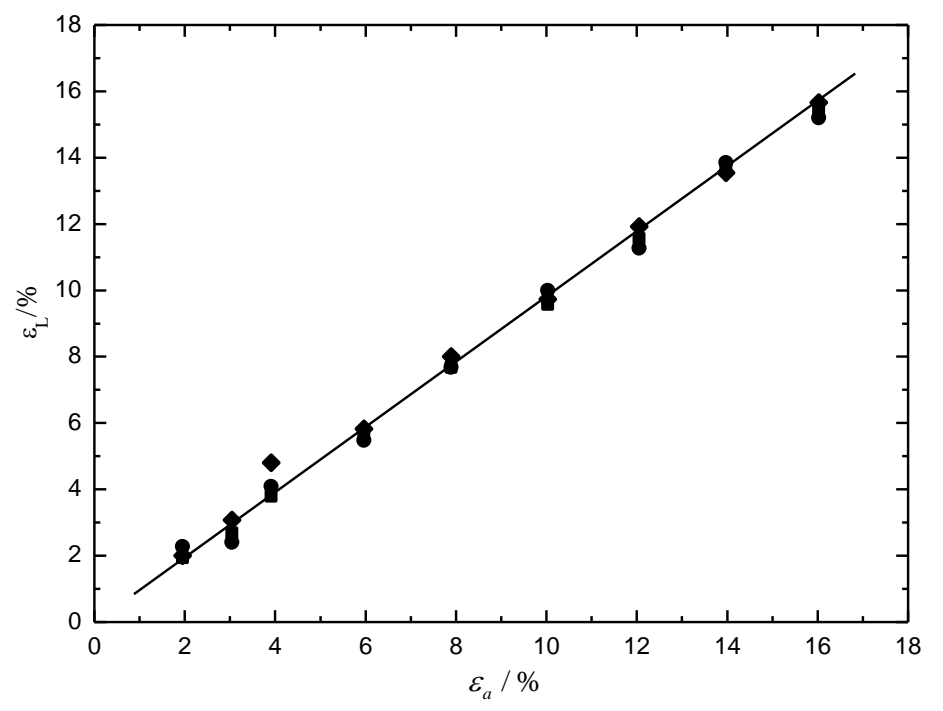

Figure 5. Relationship between axial accumulative strain and axial total strain.

Under lower confining pressures, the cementing structure (with relatively high cement content) of the mixed lightweight soil plays the main role in bearing the load capacity, and the damage of the specimen is very small. In this condition, the EPS particles are still constrained by the cementation force, indicating that the characteristics of larger elastic deformation cannot be brought into full activity. Although the elastic deformation of the lightweight soil would mainly come from the elastic deformation of the EPS particles, the elastic strain is always at a lower level when the stress state is relatively small. Therefore, the difference of the elastic strains under different conditions is not obvious.

\subsection{Resilient Modulus}

According to the linear relationship between the axial cumulative strain and the axial total strain, a formula can be expressed as:

$$
\varepsilon_{L}=k \varepsilon_{a}
$$

where $\varepsilon_{L}$ is the axial cumulative strain, $\varepsilon_{a}$ is the axial total strain, and $k$ is the ratio of the axial cumulative strain to the axial total strain. 
Subjected to the monotonic loading, the relationship between the principal stress difference and the recoverable strain can be formulated as:

$$
\sigma_{1}-\sigma_{3}=f\left(\varepsilon_{a}\right)=g\left(\varepsilon_{h}\right)=g\left((1-k) \varepsilon_{a}\right)
$$

where $\sigma_{1}$ and $\sigma_{3}$ are the principal stresses and $\varepsilon_{h}$ is the recoverable strain.

The resilient modulus of the specimen under the monotonic loading can be defined as:

$$
E_{u r}=\frac{\sigma_{1}-\sigma_{3}}{\varepsilon_{h}}=\frac{\sigma_{1}-\sigma_{3}}{(1-k) \varepsilon_{a}}
$$

The resilient modulus here can also be defined as the average of the unloading modulus and the reloading modulus [24]. The unloading modulus is the ratio of the stress at the unloading point to the recoverable strain (i.e., elastic strain), and the reloading modulus is the ratio of the stress at which it is reloaded to the unloading point to the recoverable strain. Although the elastic strain that is mentioned above is very small, the variation will have a significant influence on the resilient modulus of the lightweight soil.

In Figures 6 and 7, the resilient modulus decreases with the increasing axial total strain, and it increases with the increasing confining pressure and cement content. Similar to the dynamic modulus [25], the resilient modulus will gradually approach a same critical value of $40 \mathrm{kPa}$, even under different confining pressures and cement contents in this study. Due to the increasing axial total strain, the cementation structure of the mixed lightweight soil is gradually damaged and its strength decreases step by step. Simultaneously, the constraint on the deformation of EPS particles is also reduced, and its elastic deformation is playing an increasingly important role afterwards. When the cementation structure is completely destroyed, the mixed lightweight soil tends to be loose, and whose resilient modulus arrives at a same level.

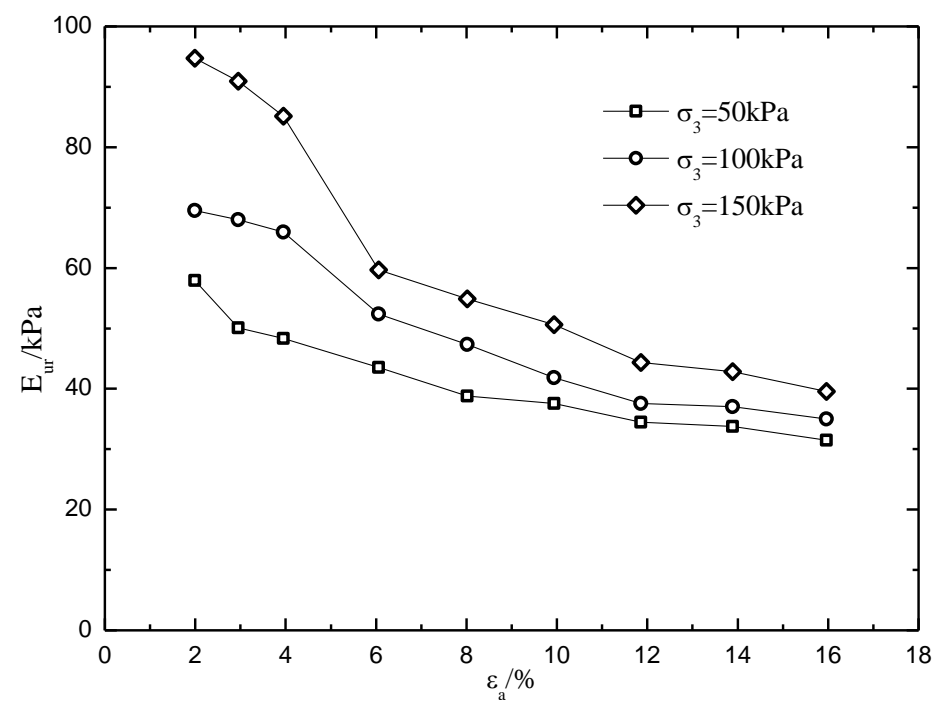

Figure 6. Resilient modulus versus axial total strain under different confining pressures. 


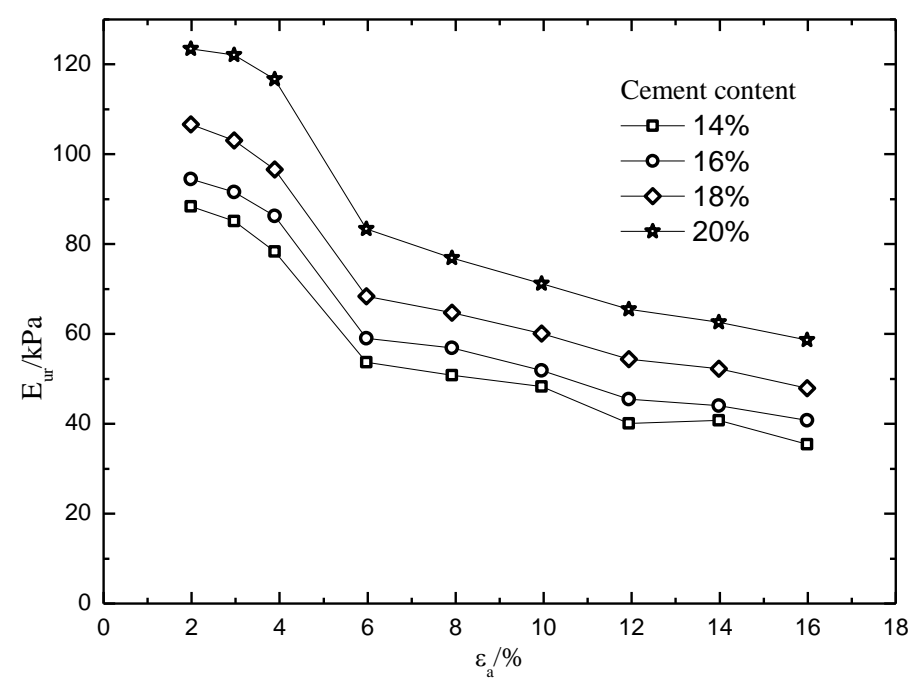

Figure 7. Resilient modulus versus axial total strain under different cement contents.

On the one hand, the increasing confining pressure enhances the restraint on the specimen and then on the EPS particles. On the other hand, the increasing confining pressure enhances the destruction of the cementation structure and thus weakens the restraint on the EPS particles. Therefore, the combination of the two actions increases the strength of the mixed lightweight soil increases, weakens the restraint, but increases the elastic deformation of the EPS particles. Obviously, the multiple of strength increase is larger than the multiple of elastic deformation increase, and this can be easily found in Figure 8.

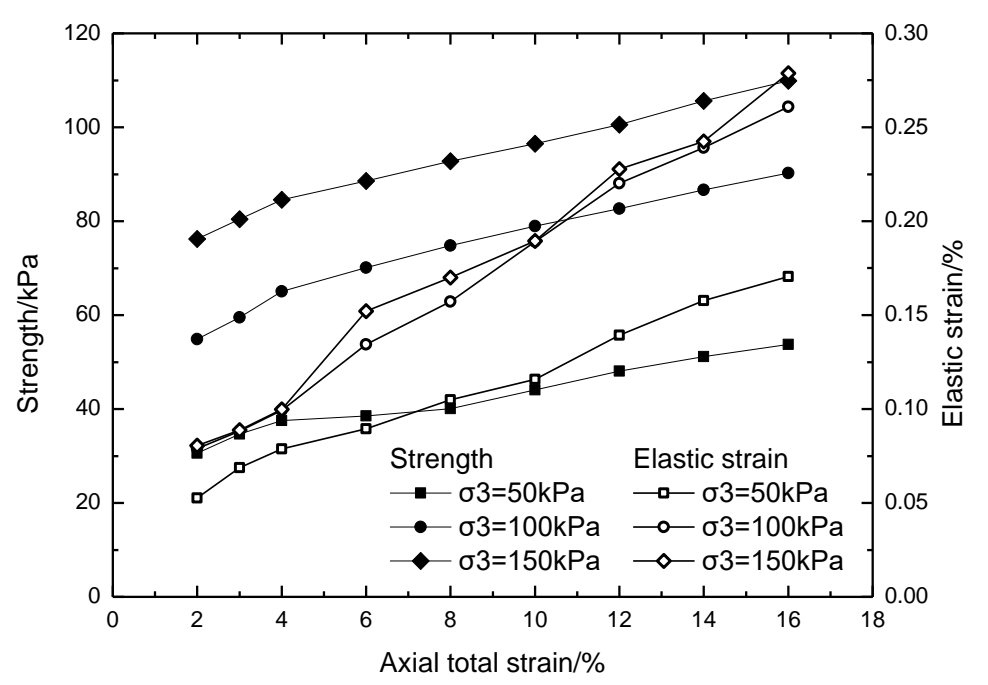

Figure 8. Strength and elastic strain corresponding to the resilient modulus.

With increasing cement content, the cementation becomes stronger, as well as the strength of the specimen. Deformation of the EPS particles is constrained, indicating that the elastic deformation would be reduced, which contributes to the increase of resilient modulus of the lightweight soil. Under the tested confining pressures and mixture ratios, the relationship between the resilient modulus and the axial total strain can be established as:

$$
E_{u r}=a \varepsilon_{a}^{b}
$$

where $a$ and $b$ are all the fitting parameters and they are related to the confining pressure and cement content. Subsequently, the fitting relation can be formulated by the following function: 


$$
\left\{\begin{array}{l}
a=a_{1} a_{w}^{2}+b_{1} a_{w}+c_{1} \\
b=a_{2} a_{w}^{2}+b_{2} a_{w}+c_{2}
\end{array}\right.
$$

where $a_{1,2}, b_{1,2}$, and $c_{1,2}$ are all the fitting coefficients related to the confining pressure. Then, a general formula can be deduced as:

$$
y=\alpha \sigma_{3}^{2}+\beta \sigma_{3}+\gamma
$$

where $\sigma_{3}$ is the confining pressure, $\alpha, \beta$, and $\gamma$ are also the fitting coefficients, which can be deduced in Table 2.

Table 2. Deduced values of $\alpha, \beta$, and $\gamma$.

\begin{tabular}{ccccccc}
\hline \multirow{2}{*}{ Fitting Parameters } & \multicolumn{3}{c}{ LSES } & \multicolumn{3}{c}{ LCES } \\
\cline { 2 - 7 } & $\alpha$ & $\boldsymbol{\beta}$ & $\gamma$ & $\boldsymbol{\alpha}$ & $\boldsymbol{\beta}$ & $\gamma$ \\
\hline$a_{1}$ & 4.082 & -871.570 & $47,389.000$ & -0.887 & 130.350 & 4556.900 \\
$b_{1}$ & -1.372 & 295.900 & $-15,571.000$ & 0.194 & -23.908 & -1809.500 \\
$c_{1}$ & 0.118 & -25.067 & 1346.900 & -0.005 & 0.104 & 238.290 \\
$a_{1}$ & -0.032 & 7.820 & -446.140 & 0.003 & -0.125 & -45.564 \\
$b_{2}$ & 0.011 & -2.769 & 159.200 & -0.000 & -0.140 & 23.901 \\
$c_{2}$ & -0.001 & 0.243 & -14.364 & -0.000 & 0.030 & -3.080 \\
\hline
\end{tabular}

Note: LSES is the sand mixed lightweight soil, LCES is the silty clay mixed lightweight soil.

As illustrated in Figure 9, the resilient modulus of sandy lightweight soil is higher than that of silty clay lightweight soil under confining pressures of $50 \mathrm{kPa}$ and $150 \mathrm{kPa}$. The same condition also applies to the strength and recoverable elastic strain of the lightweight soil samples (as shown in Table 3). For the basic physical characteristics, the granular sand has smaller specific surface area and less activity than the silty clay. When cement is added, the granular sand and the cement have a rapid cementation speed with the help of water. The more cemented material is produced, the higher cementation strength would be generated to constrain the deformation of the EPS particles, resulting in smaller elastic deformation and higher resilient modulus. Although the silty clay is flattened with strong activity, the cement's hydrolysis and the hydration reactions mainly happen around a certain active medium. Therefore, the reaction is slow but needs a long time, and less cementing material is produced within a certain curing time. Moreover, the cemented silty clay has a lower strength to restrict the EPS particles, resulting in a lower strength than the sandy lightweight soil, as well as the resilient modulus. Due to the existence of a layer of bound water film around the fine-grained soil particle, silty clay has better deformation adaptability than sand, indicating that the silty clay lightweight soil has lower strength and resilient modulus than that of the sandy lightweight soil.

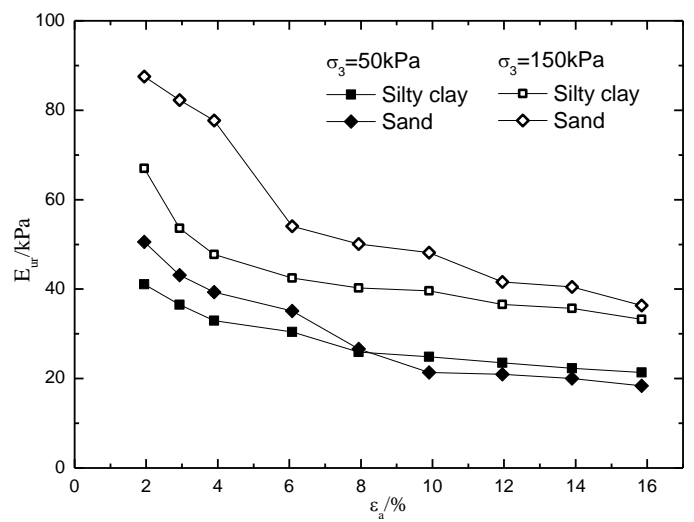

(a)

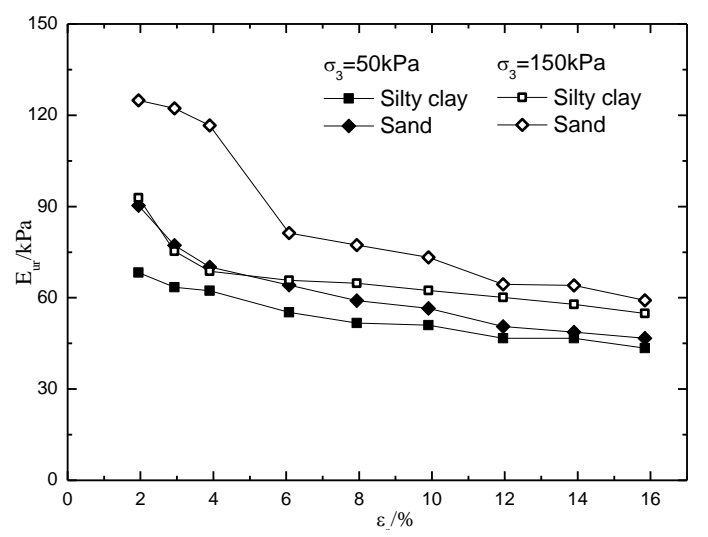

(b)

Figure 9. Resilient modulus versus axial total strain under different confining pressures: (a) aw $=14 \%$; (b) aw $=20 \%$. 
As shown in Figure 9a, with a lower confining pressure of $50 \mathrm{kPa}$ and a smaller cement content of $14 \%$, when the axial total strain of the specimen exceeds $8 \%$, the resilient modulus of the sandy lightweight soil is smaller than that of the silty clay lightweight soil. This is rather unusual in the overall condition of these tested samples. When the shear deformation of the specimen becomes larger (i.e., the axial total strain exceeds $8 \%$ ), the degree of particle breakage increases, and the sandy lightweight specimen starts to loosen, resulting in a decrease in the cohesion, as well as the resilient modulus. Although the same thing happened to the silty clay lightweight soil, the above reduction in cohesion and resilient modulus under the same shear deformation are relatively smaller than the sandy soils. However, such a phenomenon does not exist when the confining pressure and cement content are higher, indicating that the constraint of higher confining pressure excels the loss of cohesion that is caused by shear deformation for sandy lightweight soil, and the higher cement content contributes to the increasing of cementing force in a short term. Within a limited curing time (7 days or 14 days), the resilient modulus of the sandy lightweight soil is usually larger that of silty clay type mixture (see Table 3).

Table 3. Strength and elastic strain corresponding to the resilient modulus in Figure 7.

\begin{tabular}{|c|c|c|c|c|c|c|c|c|}
\hline \multirow{3}{*}{$\varepsilon_{a} / \%$} & \multicolumn{4}{|c|}{$a_{w}=14 \%, \sigma_{3}=50 \mathrm{kPa}$} & \multicolumn{4}{|c|}{$a_{w}=14 \%, \sigma_{3}=150 \mathrm{kPa}$} \\
\hline & \multicolumn{2}{|c|}{ Strength/kPa } & \multicolumn{2}{|c|}{$\varepsilon_{h} / \%$} & \multicolumn{2}{|c|}{ Strength $/ \mathbf{k P a}$} & \multicolumn{2}{|c|}{$\varepsilon_{h} / \%$} \\
\hline & LSES & LCES & LSES & LCES & LSES & LCES & LSES & LCES \\
\hline 2 & 26.71 & 22.00 & 0.0528 & 0.0537 & 70.77 & 64.71 & 0.0809 & 0.0964 \\
\hline 3 & 30.03 & 26.11 & 0.0696 & 0.0707 & 74.26 & 68.27 & 0.0893 & 0.1286 \\
\hline 4 & 31.73 & 30.41 & 0.0801 & 0.0926 & 78.36 & 72.33 & 0.1005 & 0.1507 \\
\hline 6 & 32.03 & 31.91 & 0.0911 & 0.0926 & 82.93 & 76.16 & 0.1526 & 0.1806 \\
\hline 8 & 33.17 & 33.09 & 0.1254 & 0.1258 & 86.15 & 80.38 & 0.1718 & 0.2006 \\
\hline 10 & 34.74 & 33.95 & 0.1600 & 0.1370 & 90.86 & 84.83 & 0.1925 & 0.2177 \\
\hline 12 & 38.58 & 36.47 & 0.1845 & 0.1535 & 94.42 & 88.04 & 0.2319 & 0.2445 \\
\hline 14 & 41.90 & 39.54 & 0.2116 & 0.1796 & 98.31 & 92.79 & 0.2432 & 0.2641 \\
\hline \multirow[t]{2}{*}{16} & 44.69 & 42.30 & 0.2431 & 0.1956 & 102.84 & 96.44 & 0.2792 & 0.2844 \\
\hline & \multicolumn{4}{|c|}{$a_{w}=20 \%, \sigma_{3}=50 \mathrm{kPa}$} & \multicolumn{4}{|c|}{$a_{w}=20 \%, \sigma_{3}=150 \mathrm{kPa}$} \\
\hline \multirow[t]{2}{*}{$\varepsilon_{a} / \%$} & \multicolumn{2}{|c|}{ Strength/kPa } & \multicolumn{2}{|c|}{$\varepsilon_{h} / \%$} & \multicolumn{2}{|c|}{ Strength/kPa } & \multicolumn{2}{|c|}{$\varepsilon_{h} / \%$} \\
\hline & LSES & LCES & LSES & LCES & LSES & LCES & LSES & LCES \\
\hline 2 & 45.90 & 35.41 & 0.0517 & 0.0521 & 100.23 & 83.75 & 0.0803 & 0.0893 \\
\hline 3 & 50.29 & 42.30 & 0.0665 & 0.0670 & 107.24 & 92.63 & 0.0882 & 0.1223 \\
\hline 4 & 53.49 & 49.19 & 0.0774 & 0.0794 & 114.00 & 100.53 & 0.0983 & 0.1469 \\
\hline 6 & 56.06 & 56.01 & 0.0885 & 0.1018 & 121.73 & 105.70 & 0.1488 & 0.1616 \\
\hline 8 & 59.61 & 59.56 & 0.1030 & 0.1176 & 128.95 & 113.99 & 0.1673 & 0.1797 \\
\hline 10 & 63.81 & 62.91 & 0.1133 & 0.1268 & 135.03 & 121.57 & 0.1867 & 0.1989 \\
\hline 12 & 69.23 & 68.69 & 0.1378 & 0.1501 & 142.43 & 130.90 & 0.2212 & 0.2214 \\
\hline 14 & 73.90 & 72.90 & 0.1545 & 0.1578 & 149.64 & 139.36 & 0.2397 & 0.2440 \\
\hline 16 & 77.21 & 77.20 & 0.1669 & 0.1790 & 156.20 & 151.32 & 0.2705 & 0.2710 \\
\hline
\end{tabular}

Note: LSES is the sand mixed lightweight soil, LCES is the silty clay mixed lightweight soil.

\subsection{Damping Ratio}

According to the conventional definition [26], the damping ratio is related to the energy loss rate in a certain time, and the formula can be expressed as:

$$
y=\alpha \sigma_{3}^{2}+\beta \sigma_{3}+\gamma
$$

where $\lambda$ is the damping ratio, $\Delta W$ is the loss energy within a loading-unloading cycle, and $W$ is the total energy of a complete loading-unloading cycle.

In this study, the damping ratio is calculated by the energy loss rate in a loading-unloading cycle. The typical stress-strain relationship of the tested specimen can be illustrated in Figure 10. 
In a complete loading-unloading cycle, the work that is done by extra loads can be defined as: at the beginning OA section, most of the work done by external load is converted into elastic potential energy, indicating that the specimen's deformation is mainly attributed to the elastic deformation. Subsequently, in the second $\mathrm{AB}$ section, plastic deformation is produced in the specimen and it becomes larger and larger. Although, the work done by external load on the specimen is mainly consumed by the plastic deformation and the viscous resistance, there will still be a small part stored as the elastic potential energy. Within the BC section, when the external load is removed, the elastic potential energy that is stored in sections of $\mathrm{OA}$ and $\mathrm{AB}$ will be gradually released and absolutely consumed by viscous resistance.

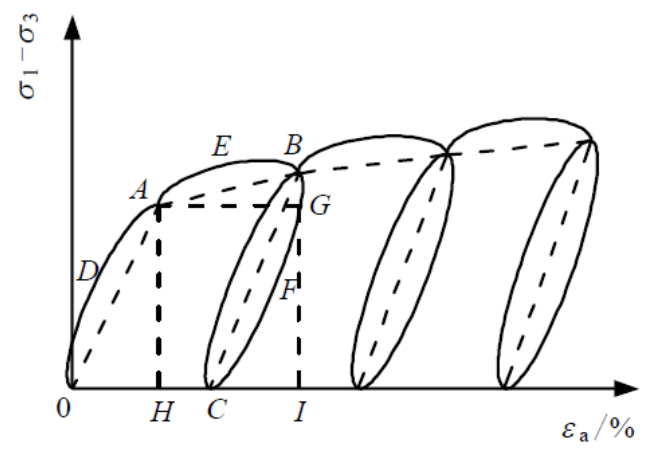

Figure 10. Simplified form of repeated loading and the stress-strain relationship.

According to the general form of stress-strain relationship and energy composition analyses, the EPS beads-mixed lightweight soil belongs to the viscoelastic plastic material. The $\Delta W$ and $W$ in Equation (7) can be calculated by the following expression:

$$
\begin{gathered}
\Delta W=S_{O D A}+S_{A E B}+S_{B F C}+S_{A G I H} \\
W=S_{O D A E B F C 0}
\end{gathered}
$$

where $S_{O D A}, S_{A E B}, S_{B F C}, S_{A G I H}$, and $S_{O D A E B F C O}$ are the areas of different regions in Figure 10. In Equation (8), the former three items are the energy consumed by damping, the last one is the energy consumed by plastic deformation. Afterwards, the damping ratio can be calculated out.

Figure 11 shows the variation of damping ratios versus axial total strains under different confining pressures, cement contents for different soil types. The damping ratio increases slowly with the increasing axial total strain, but its value ranges from 0.07 to 0.08 . However, the damping ratios of the lightweight soil obtained by Gao et al. [15] have a larger variation range from 0.05 to 0.20 when the strain increases from $1 \%$ to $10 \%$ (see Figure 11d). This is mainly due to the different test methods and the corresponding formation of tested lightweight samples, with lower cement content and higher volume occupancy of EPS beads. Although the difference of damping ratios are relatively small under different conditions in this study, there are still some characteristics that can be detected. For example, the sandy lightweight soil has lower damping ratio than the silty lightweight soil, and larger confining pressure and higher cement content obtain smaller damping ratios.

There are two kinds of damping in soils, one is the dissipation damping, and the other is the material damping. The former is caused by the diffusing of energy that is accumulated in the soil to the outside world in forms of surface wave and body wave, while the latter is generated from the friction between particles and the viscosity of pore water and air. However, this study is not focusing on the dynamic problem under the action of high frequency. The wave is not considered and the dissipation damping can be assumed to be zero, then the damping can be deduced to be a completely material damping. Actually, the bonding strength of the specimen is relatively strong due to the adopted cement contents, so there is little difference between the dislocation and slip of particles under the confining pressures and the strain levels in this study. 


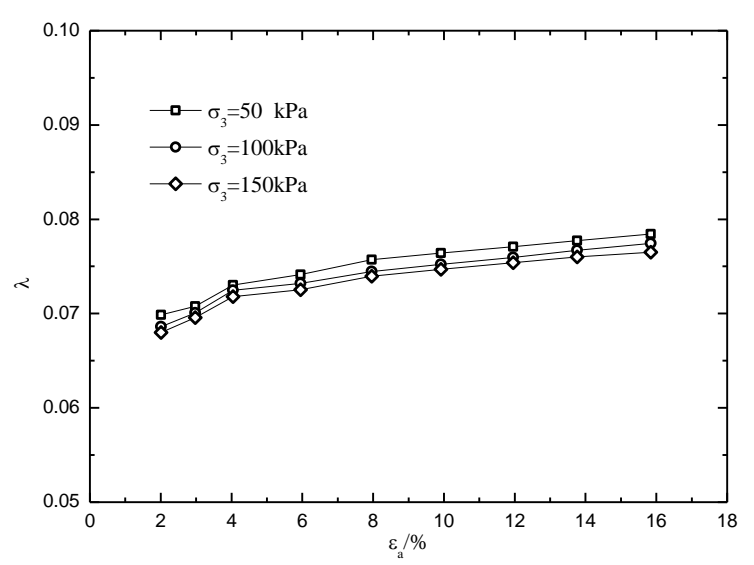

(a)

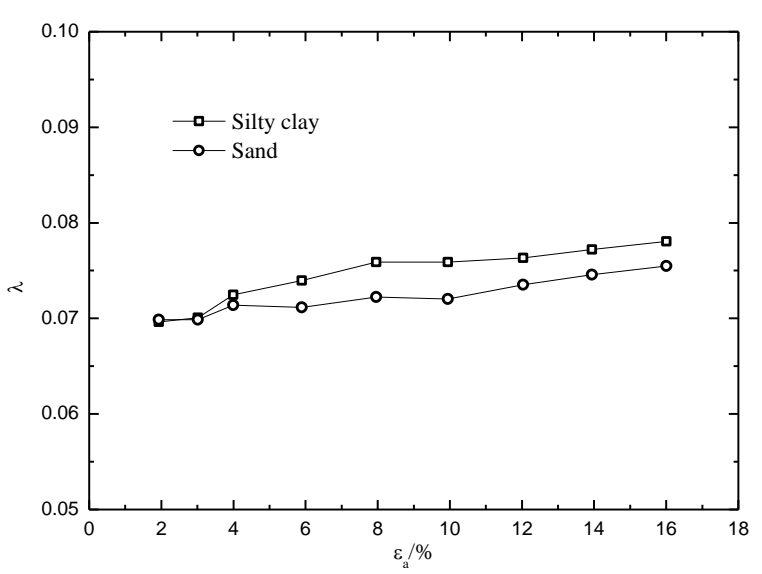

(c)

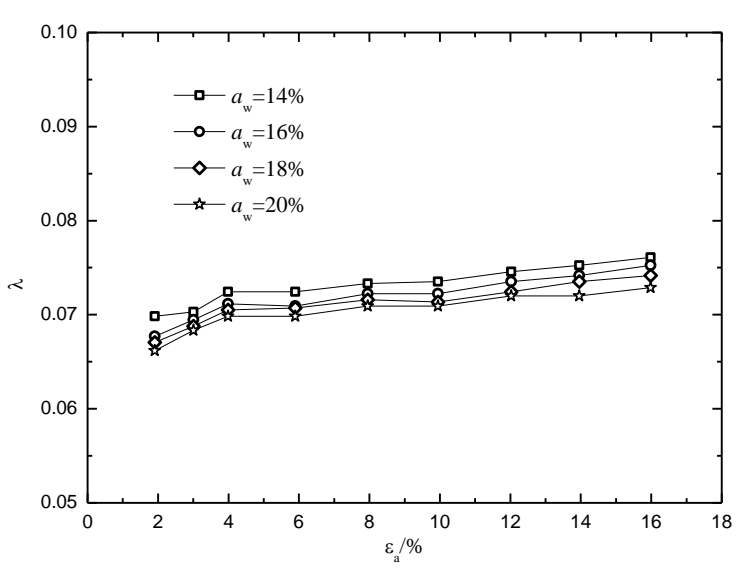

(b)

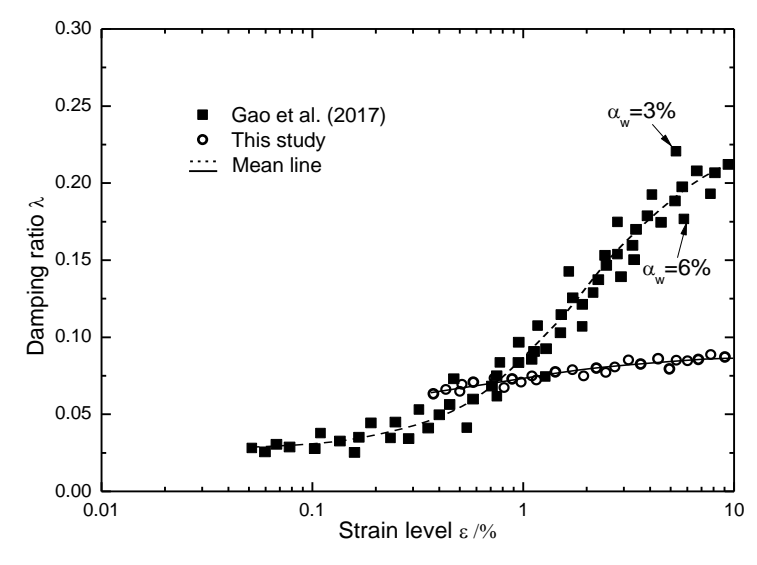

(d)

Figure 11. The damping ratio versus axial total strain under different condition: (a) Silty lightweight soil with $a_{w}=14 \%$; (b) Sandy lightweight soil with $\sigma_{3}=100 \mathrm{kPa}$; (c) Under $a_{w}=14 \%$ and $\sigma_{3}=50 \mathrm{kPa}$; and, (d) Comparison with Gao et al.'s results.

Although little differences in hydration products, pore water, and pore gas have been detected, there are still some other points worth analyzing. The larger the strain is, the greater the damage of the specimen is. The greater the dislocation and slip between particles are, the greater the friction between particles is, and the greater the material damping ratio would be. With increasing confining pressure, the specimen is compressed denser, and then the particles' dislocation and slip are decreased with smaller friction, as well as the smaller damping ratio. The same situation is still applicable to the cement content. From the previous analyses, more cementing substances are produced in the sandy lightweight soil than in the silty clay lightweight soil for a certain curing time. Therefore, the interaction between grains of sandy lightweight soil is closer and the filling degree of the void is larger. Moreover, the dislocation, slip, and friction between grains are reduced, indicating that the discharge of pore water and pore gas in the lightweight soil is increased, and then a smaller material damping ratio is obtained.

\section{Conclusions}

The characteristics of deformation and damping of the sandy and silty clay EPS beads-mixed lightweight soil were investigated, regarding the axial accumulative strain, resilient modulus, and damping ratio under different confining pressures and cement contents. The main conclusions are as follows: 
(1) Within a certain range of confining pressure, cement content, and strain level, the ratio of axial cumulative strain to axial total strain, which is less affected by soil category and loading factor, remains at a constant value. A linear relationship between the two can be deduced and the formula for resilient modulus can be derived indirectly.

(2) The springback deformation of EPS beads-mixed lightweight soil mainly comes from the springback deformation of the EPS particles. Due to the particularity of the lightweight soil, the confining pressure will cause certain damage to the cemented structure of the specimen, reducing the restriction on EPS particles but increasing the constraint on the specimen at the same time. However, the comprehensive effect depends on the strain level and the confining pressure.

(3) The resilient modulus of the EPS beads-mixed lightweight soil decreases with the increasing axial total strain and increases with the increasing confining pressure and cement content. When the axial total strain exceeds $8 \%$, the resilient modulus of the sandy lightweight soil is smaller than the silty clay lightweight soil. However, when the axial total strain is smaller than $8 \%$, the opposite results can be observed.

(4) The damping ratio of the EPS lightweight soil increases with the increasing axial total strain but decreases with the increasing confining pressure and cement content. Although the damping ratio of the sandy lightweight soil is smaller than that of the silty lightweight soil, the variation and difference are very small, and its value remains stable at around 0.07 to 0.08 .

Author Contributions: Conceptualization, W.L., L.M. and J.Z.; methodology, W.L.; software, Y.Z.; validation, W.L. and L.M.; formal analysis, J.Z.; investigation, W.L.; resources and data curation, L.M.; writing一original draft preparation and writing-review and editing, W.L. and J.Z.; supervision, J.L.

Funding: This research was funded by the National Key Research and Development Program of China (Grant No. 2017YFC0805307), National Natural Science Foundation of China (Grant No. 51508279, 51578292, 51478054 and 51878078), Jiangsu Provincial Natural Science Fund Projects (Grant No. BK20150885), Excellent Youth Foundation of Natural Science Foundation of Hunan Province (Grant No. 2018JJ1026) Key Project of Education Department of Hunan Province (Grant No. 17A008). Open Research Fund of Science and Technology Innovation Platform of State Engineering Laboratory of Highway Maintenance Technology Changsha University of Science \& Technology (Grant No. kfj150103), Ministry of Housing and Urban-Rural Development of China (2018-K4-008) and Open Fund of National Engineering Laboratory of Highway Maintenance Technology, Changsha University of Science \& Technology (Grant No. kfj170101).

Acknowledgments: The authors still wish to thank the graduate students at who helped with specimen preparing and testing.

Conflicts of Interest: The authors declare no conflict of interest. The funders had no role in the design of the study; in the collection, analyses, or interpretation of data; in the writing of the manuscript, or in the decision to publish the results.

\section{References}

1. Cao, W.; Shi, Q. Settlements of Existing and Widened Embankments over Soft Soils. Adv. Mater. Res. 2012, 446-449, 1167-1171. [CrossRef]

2. Zhang, J.; Peng, J.; Li, J.; Zheng, J.; Yao, Y. Characterization of stress and moisture-dependent resilient behaviour for compacted clays in south China. Road Mater. Pavement 2018. [CrossRef]

3. Lu, W.; Miao, L. A simplified 2-D evaluation method of the arching effect for geosynthetic-reinforced and pile-supported embankments. Comput. Geotech. 2015, 65, 97-103. [CrossRef]

4. King, D.; Bouazza, A.; Gniel, J.; Rowe, R.; Bui, H. Geosynthetic reinforced column supported embankments and the role of ground improvement installation effects. Can. Geotech. J. 2018, 55, 792-809. [CrossRef]

5. Stark, T.; Horvath, J.; Leshchinsky, D. Geo-Foam Application in the Design and Construction of Highway Embankments; NCHRP Project No. 24-14; TRB: Washington, DC, USA, 2004.

6. Kim, Y.; Kim, H.; Lee, G. Mechanical behavior of lightweight soil reinforced with waste fishing net. Geotext. Geomembr. 2008, 26, 512-518. [CrossRef]

7. Frydenlund, T. Expanded Polystyrene-A Lighter Way across Soft Ground; International Report No. 1502; Norwegian Road Research Laboratory: Oslo, Norway, 1991. 
8. Hatami, K.; Witthoeft, A.F. Reduction of backfill earth pressure in reinforced soil walls using geofoam. In Proceedings of the 86th TRB Annual Meeting, Transportation Research Board, Washington, DC, USA, 21-25 January 2007.

9. Ikizler, S.; Aytekin, M.; Nas, M. Laboratory study of expanded polystyrene (EPS) geofoam used with expansive soils. Geotext. Geomembr. 2008, 26, 189-195. [CrossRef]

10. Tsuchida, T. Super geo-material project in coastal zone. In Proceedings of the International Symposium on Ocean Space Utilization, COSU'95, Yokohama, 1995; pp. 22-31.

11. Miki, H. An overview of lightweight banking technology in Japan. In Proceedings of the International Symposium on EPS Construction Method (EPSTokyo'96), Tokyo, Japan, 2-4 October 1996; pp. 9-30.

12. Liu, H.; Deng, A.; Chu, J. Effect of different mixing ratios of polystyrene pre-puff beads and cement on the mechanical behavior of lightweight fill. Geotext. Geomembr. 2006, 24, 331-338. [CrossRef]

13. Miao, L.; Wang, F.; Han, J.; Lu, W.; Li, J. Properties and applications of cement-treated sand-expanded polystyrene bead lightweight fill. J. Mater. Civ. Eng. 2013, 25, 86-93. [CrossRef]

14. Minegishi, K.; Makiuchi, K.; Takahashi, R. Strength-deformation characteristics of EPS beads-mixed lightweight geomaterial subjected to cyclic loadings. In Proceedings of the International Workshop on Lightweight Geo-Materials, Tokyo, Japan, 26-27 March 2002; pp. 119-125.

15. Gao, H.; Bu, C.; Wang, Z.; Shen, Y.; Chen, G. Dynamic characteristics of expanded polystyrene composite soil under traffic loadings considering initial consolidation state. Soil Dyn. Earthq. Eng. 2017, 102, 86-98. [CrossRef]

16. El-Sherbiny, R.; Ramadan, S.; El-Khouly, M. Dynamic properties of sand-EPS bead mixtures. Geosynth. Int. 2018, 25, 456-470. [CrossRef]

17. Alaie, R.; Chenari, R. Cyclic and post-cyclic shear behavior of interface between geogrid and EPS beads-sand backfill. KSCE J. Civ. Eng. 2018, 22, 3340-3357. [CrossRef]

18. ASTM D2487-11. Standard Practice for Classification of Soils for Engineering Purposes; American Society for Testing and Materials: West Conshohocken, PA, USA, 2011.

19. Onishi, K.; Tsukamoto, Y.; Saito, R.; Chiyoda, T. Strength and small-strain modulus of lightweight geomaterials: Cement-stabilised sand mixed with compressible expanded polystyrene beads. Geosynth. Int. 2010, 17, 380-388. [CrossRef]

20. Gao, H.M.; Liu, J.Y.; Liu, H.L. Geotechnical properties of EPS composite soil. Int. J. Geotech. Eng. 2011, 5, 69-77. [CrossRef]

21. Edinçliler, A.; Özer, A.T. Effects of EPS bead inclusions on stress-strain behaviour of sand. Geosynth. Int. 2014, 21, 89-102. [CrossRef]

22. Zhang, J.; Li, J.; Yao, Y.S.; Zheng, J.L.; Gu, F. Geometric anisotropy modeling and shear behavior evaluation of graded crushed rocks. Constr. Build. Mater. 2018, 183, 346-355. [CrossRef]

23. ASTM D4767-11. Standard Test Method for Consolidated Undrained Triaxial Compression Test for Cohesive Soils; American Society for Testing and Materials: West Conshohocken, PA, USA, 2011.

24. Zhang, J.; Peng, J.; Li, J.; Zheng, J. Variation of resilient modulus with soil suction for cohesive soils in south China. Int. J. Civ. Eng. 2018, 16, 1655-1667. [CrossRef]

25. Gao, Y.F.; Wang, S.M.; Chen, C.B. A united deformation-strength framework for Lightweight Sand-EPS Beads Soil (LSES) under cyclic loading. Soil Dyn. Earthq. Eng. 2011, 31, 1144-1153. [CrossRef]

26. Rollins, K.M.; Evans, M.D.; Diehl, N.B.; Daily, W.D. Shear modulus and damping relationships for gravels. J. Geotech. Geoenviron. Eng. 1998, 124, 396-405. [CrossRef]

(C) 2019 by the authors. Licensee MDPI, Basel, Switzerland. This article is an open access article distributed under the terms and conditions of the Creative Commons Attribution (CC BY) license (http://creativecommons.org/licenses/by/4.0/). 